\title{
EDUCAÇÃO E SEXUALIDADE: UM ESTUDO COM PROFESSORES DE ALUNOS SURDOS
}

\author{
Victor Hugo de Oliveira Henrique* \\ Edna Lopes Hardoim**
}

\begin{abstract}
RESUMO: A sexualidade compreende aspectos biológicos, psicológicos e socioculturais. Ela é desenvolvida ao longo da vida e inicia-se a partir das primeiras experiências afetivas do bebê. Objetivando compreender 0 entendimento de sexualidade dos professores de centro de apoio à deficientes auditivos, foi aplicado um questionário semi-estruturado. Todos foram unanimes quanto a importância da temática sexualidade ser trabalhada na escola. Quando questionados se já trabalharam a temática sexualidade em sala de aula a maioria disse que sim, e uma minoria disse que não. Dentro os que responderam abordar a temática em sala de aula, foram relatados os assuntos mais abordados: prevenção de Doenças Sexualmente Transmissíveis e gravidez indesejada, diversidade sexual e de gênero. Os recursos mais usados pelos professores são palestras/oficinas com profissionais da área e filmes/documentários. Percebe-se a necessidade de uma prática interdisciplinar no que toca à sexualidade, e de que todos os profissionais da educação estejam preparados para falar, partindo, ou não, do conteúdo de suas disciplinas.
\end{abstract}

Palavras-chave: Sexualidade; Educação; Professores; Alunos surdos.

\begin{abstract}
The sexuality includes biological, psychological and sociocultural aspects. It is developed throughout life and starts from the first affective experiences of the baby. Aiming to understand the apprehension of sexuality a questionnaire was applied to teachers of a deaf support center. All were unanimous about the importance of the sexuality be worked at school. When asked if they have worked the theme sexuality in the classroom the majority said yes, and a minority said no. Inside the respondents address the issue in the classroom, the most discussed topics were reported: prevention of sexually transmitted diseases and unwanted pregnancies, sexual and gender diversity. The funds most used by teachers are lectures/workshops with professionals and films/documentaries. We realize the need for an interdisciplinary practice

\footnotetext{
* Graduado em Ciências Biológicas pelo Instituto de Biociências da Universidade Federal de Mato Grosso (UFMT). Mestrando em Educação pelo Instituto de Biociências da Universidade Estadual Paulista "Júlio de Mesquita Filho" (Unesp) - Campus de Rio Claro. E-mail: hugo31_oh@hotmail.com

* Doutorado em Ecologia e Recursos Naturais pela Universidade Federal de São Carlos (UFSCar). Docente do Departamento de Botânica e Ecologia - Instituto de Biociências Universidade Federal de Mato Grosso (UFMT).
} 
when it comes to sexuality, and that all education professionals are prepared to talk, starting or not the content of their disciplines.

Keywords: Sexuality; Education; Teachers; Deaf students.

\section{INTRODUÇÃO}

Os processos formais de ensino-aprendizagem tem início quando surge uma apropriação dos alunos sobre um determinado assunto abordado pelo professor, que possui um papel importante nesta relação. No caso do ensino de Ciências, o docente deve desenvolver estratégias para efetivar a transposição didática do tema, ou seja, estratégias metodológicas e didáticas que irão facilitar o entendimento do conhecimento científico, associando-o ao cotidiano do aluno. O saber acadêmico serve de base para legitimar o saber ensinado, cuja mediação é feita pelo professor (RODRIGUES; SCHEID, 2008).

No âmbito da sexualidade percebe-se que não é uma tarefa fácil, pois em muitos casos, a família simplesmente se ausenta das discussões sobre o tema por medo ou pela falta de informações necessárias, como se isso fosse estimular excessivamente a sexualidade dos filhos. Este fato faz com que as dúvidas referentes ao tema sejam trabalhadas na escola. Esta, na maioria das vezes, não está preparada, embora esse seja um dos temas transversais propostos pelos Parâmetros Curriculares Nacionais (BRASIL, 1997) a ser trabalhado na educação básica (RODRIGUES; SCHEID, 2008).

No decorrer dos anos, percebeu-se que a educação sexual obteve um inegável desenvolvimento no âmbito escolar, tornando-se uma medida muito significativa para desconstruir diversos mitos e preconceitos que foram sendo (e são) produzidos na escola. Desse modo, os/as docentes precisam se preparar para abordar e discutir estes e outros temas de extrema relevância social (SOUZA; SANTOS, 2012).

A Educação Sexual pode ser desenvolvida com base nos Parâmetros Curriculares Nacionais. De acordo com os PCN, os trabalhos referentes à educação sexual devem ser realizados em três eixos norteadores, são eles 
"corpo: matriz da sexualidade", "prevenção de doenças sexualmente transmissíveis" e "relações de gênero" (BRASIL, 1997).

Dentro da educação sexual, aborda-se a sexualidade, que está presente em todas as faixas etárias, e pode ser compreendida por meio de seus aspectos biológicos, psicológicos e socioculturais e corresponde um conjunto de concepções e valores que envolvem a intencionalidade humana e a expressão afetiva de cunho social e histórico. Ela não é apenas uma questão pessoal, mas uma questão política e social, uma "invenção social" que compõe-se a partir de uma rede de discursos diretamente relacionados à forma como a sociedade se organiza socialmente (FOUCAULT, 2007).

A sexualidade envolve, então, uma amplitude de condutas humanas, para além de sua genitalidade e não deve ser entendida, exclusivamente, como sinônimo de sexo, relação sexual, orgasmo, órgãos sexuais, mas sim, na sua dimensão ampla e cultural que abrange diferentes sentidos, como o amor, relacionamentos afetivos e sexuais, a sensualidade, o erotismo e o prazer, a expressão da identidade e dos papéis sexuais. Ela inicia-se a partir das primeiras experiências afetivas do bebê com os pais ou com qualquer outra pessoa que esteja em constante contato com ele (MAIA; ARANHA, 2005).

A sexualidade envolve não apenas a conduta sexual do indivíduo, o ato sexual e a reprodução, mas também, tudo aquilo que remete às situações que nos proporcionam prazer, como os afetos, desejos, a nossa relação com o próprio corpo, as relações interpessoais, bem como o papel sexual que a pessoa exerce (SCHLIEMANN, 2005)

Quando se trata de sua expressão por pessoas surdas, normalmente, o que acontece é a desconsideração. Professores e profissionais de saúde não têm desenvolvido competência para lidar com essa temática, sobretudo, quando se refere às pessoas com necessidades especiais.

No entanto, é importante que o professor expanda seus conhecimentos acerca do assunto, objetivando de auxiliar os alunos, respondendo às dúvidas de forma esclarecedora, respeitando a opinião de cada educando. Se o educador não for preparado e não souber fazer uso das informações disponibilizadas sobre a temática, poderá transportar seus valores, crenças e 
opiniões como verdades absolutas, não permitindo aos alunos a autonomia para desenvolver seu conhecimento (RODRIGUES; WECHSLER, 2014).

No passado falar de sexualidade dentro do contexto da escola com os alunos era uma afronta para a sociedade e o professor era punido de alguma forma. Com isso, questões sobre a sexualidade do aluno eram omitidas dentro da instituição escolar. Segundo Tiba (1994):

Durante muito tempo, a sexualidade foi solenemente ignorada pelas escolas. Os professores agiam como se seus alunos fossem seres assexuados, mesmo quando chegavam à adolescência. Não podia ser diferente, afinal, toda sociedade o tema sexo entre quatro paredes. O melhor método, portanto era não tocar no assunto e deixar que a natureza se encarregasse de ensinar os alunos o que estava se passando. E como a ordem era reprimir a sexualidade, melhor seria não tocar no assunto para não despertá-la.

Notadamente observa-se que durante anos o tabu, o preconceito, o medo, o despreparo e os mitos tomavam conta do tema sexualidade, e que a escola, especificamente, os professores camuflavam 0 assunto com as censuras sublimadas. Uma parcela da sociedade repudiava qualquer tentativa de discussão ou debate no tocante desse assunto, que deveria ser reprimido para não corromper os adolescentes. Assim, essa cultura assolou de geração a geração (BRÍCIO; LEMOS; MAUÊS, 2012).

Atualmente vivemos em uma época de excessos de estímulos sexual, mas sem uma preocupação com a segurança. A televisão, o cinema, a imprensa, a propaganda, inundando o cotidiano dos jovens com apelos sexuais jamais vistos por outra geração. E é daí que nasce a fantasia de que toda relação sexual é maravilhosa, visto que o adolescente se deixa influenciar por esse bombardeio. Por este princípio, percebe-se que o espaço da escola deve ser valorizado para se discutir questões em torno da sexualidade, não como controladora da vontade do sujeito, mas, como instância propiciadora de reflexão sobre a temática.

É preciso que os (as) docentes assumam o desafio de garantir a todos os alunos o direito a uma educação de qualidade, que não pode ser 
prejudicada seja pela cor da pele, orientação sexual, identidade de gênero, entre outros fatores.

Com base nessa temática, o trabalho objetivou investigar como os professores do Centro Estadual de Apoio ao Deficiente Auditivo (CEAADA) lidam com a temática sexualidade com seus alunos.

\section{SEXUALIDADE E SURDEZ}

A todo momento nós nos confrontamos com questões ligadas à sexualidade, porém, a questão ainda é considerada por muitos como um desafio, principalmente aos educadores. Mas por que abordar a questão da sexualidade se torna um desafio?

Essa temática não é simples. Nunes (2005) afirma que há um certo estranhamento do ser humano com sua própria sexualidade, dimensão que envolve valores morais, que determinam comportamentos, usos e costumes sociais que relacionam mais de uma pessoa.

Um estudo feito no município de Porteirinha-MG, sobre sexualidade, mais precisamente sobre orientação sexual, apresentou que os professores de ciências sentem falta de recurso didático específico para trabalhar esse tema em sala de aula e relatam também a incompreensão dos pais sobre o assunto, a existência de preconceitos, além de questões religiosas, timidez e até insegurança em debater informações sobre o tema (ALVES. CHAVES, 2007).

Nas últimas décadas provocaram transformações enormes na compreensão e na maneira de viver a sexualidade e estas se refletem nos valores, nos comportamentos, na linguagem, no modo de vestir, nas músicas, nos filmes, bem como nos relacionamentos, entre outros, ou seja, vivemos num ambiente "sexualizado" que torna necessária uma reflexão sobre a sexualidade humana, pois ela faz parte do nosso cotidiano (NUNES, 2005).

Tendo em vista que sexualidade pode ser compreendida por meio de aspectos biológicos, psicológicos e socioculturais, deve-se trabalhar questões nas escolas que envolvam a reflexão de modo individual e coletivo. Este exercício permitirá ao aluno o reconhecimento enquanto sujeito de sua própria 
sexualidade, construindo práticas positivas e saudáveis para 0 desenvolvimento de sua vida (FIGUEIRÓ, 2006).

Faz-se também necessário o entendimento de que não nascemos homens ou mulheres, mas sim machos e fêmeas da espécie humana. Acabamos assim nos produzindo enquanto homens e mulheres na relação com outros seres humanos. Somos então capazes de dar sentido, significado, atribuir valores, regulamentos e normatizar os relacionamentos afetivos, amorosos e sexuais, pois cada um de nós, em cada tempo e lugar, cria, recria e busca formas para viver e expressar a sexualidade. (BRASIL, 1997). Logo, propor que a escola trate as questões da sexualidade numa perspectiva dos direitos do cidadão e sob os princípios da eqüidade, insere imediatamente em discussão o professor enquanto Educador Sexual.

\section{PROCEDIMENTOS METODOLÓGICOS}

\section{Local de estudo}

O trabalho foi realizado no CEAADA - Centro Estadual de Atendimento e Apoio ao Deficiente Auditivo, localizado no município de Cuiabá - MT.

O CEAADA foi fundado em 20 de janeiro de 2000. Iniciou seu funcionamento com a Educação Básica, atendendo a Educação Infantil, Ensino Fundamental e Educação de Jovens e Adultos dentro da modalidade da Educação Especial, com uma demanda especifica de alunos surdos (SEDUC MT)

Foi, o primeiro Centro de Atendimento Educacional a crianças e jovens surdos do estado de Mato Grosso, a partir de 0 (zero) ano, atende e apoia o aluno e a família, composto por uma equipe multidisciplinar, composta por fonoaudiólogos, psicólogos, assistentes sociais, psicopedagogos e com professores capacitados na área. O centro também oferece cursos de capacitação para profissionais da educação e para a comunidade externa em LIBRAS (Língua Brasileira de Sinais). 


\section{Coleta e análise dos dados}

A pesquisa corresponde em um trabalho de análise qualitativa, que se caracteriza por uma apreensão de significados nas respostas dos sujeitos, de acordo com o contexto que ele está inserido buscando respostas para as questões da pesquisa (LUDKE \& ANDRÉ, 1986).

Foi aplicado um questionário com perguntas fechadas (4) e abertas (6), para 10 professores do CEAADA, e que após a explicação do objetivo do estudo aceitaram de livre e espontânea vontade participar da mesma assinando o Termo de Consentimento Livre e Esclarecido (TCLE). De início o objetivo era trabalhar somente com os professores de Ciências e Biologia, mas tendo em vista que a temática Sexualidade é transversal, deve ser trabalhada por toda a comunidade escolar, dessa forma, os questionários também foram aplicados para professores das outras disciplinas.

O uso de questionários, segundo Gil (1999, p.128) pode ser considerado "como a técnica de investigação composta por um número mais ou menos elevado de questões apresentadas por escrito às pessoas, tendo por objetivo 0 conhecimento de opiniões, crenças, sentimentos, interesses, expectativas, situações vivenciadas etc.". Assim, nas questões de cunho empírico, é o questionário uma técnica que servirá para coletar as informações da realidade que o cerca. O mesmo autor supracitado (p. 128/129) apresenta as seguintes vantagens do questionário sobre as demais técnicas de coleta de dados:

a) possibilita atingir grande número de pessoas, mesmo que estejam dispersas numa área geográfica muito extensa, já que o questionário pode ser enviado pelo correio; b) implica menores gastos com pessoal, posto que o questionário não exige $o$ treinamento dos pesquisadores; c) garante $o$ anonimato das respostas; d) permite que as pessoas o respondam no momento em que julgarem mais conveniente; e) não expõe os pesquisadores à influência das opiniões e do aspecto pessoal do entrevistado (GIL, 1999 p. 128/129) 


\section{RESULTADOS E DISCUSSÕES}

A maioria dos professores entrevistados possuíam pós-graduação em nível de especialização (8) e tinham formação inicial em diversas áreas: Biologia (1), Pedagogia (4), Letras/Literatura (2), Letras/Espanhol (1), Psicologia (1), Educação Física (1) e Geografia (1).

Todos os professores (100\%) acreditam que a temática sexualidade deve ser trabalhada na escola.

Sendo a sexualidade entendida como uma construção social, histórica e cultural, sente-se a necessidade de que seja discutida na escola, que se trada de um espaço privilegiado para o tratamento pedagógico desse desafio educacional contemporâneo (NOGUEIRA, 2010).

Quando questionados se já trabalharam a temática sexualidade em sala de aula a maioria disse que sim (7), e uma minoria disse que não (3). Dentro os que responderam abordar a temática em sala de aula, foram relatados os assuntos mais abordados, que são referentes à prevenção de Doenças Sexualmente Transmissíveis e à gravidez indesejada (7), à diversidade sexual e de gênero (2) e somente um professor não respondeu a essa questão. Os recursos mais usados pelos professores são palestras/oficinas com profissionais da área (6), filmes/documentários (2) e dois não responderam a essa questão.

Tentar compreender as relações humanas e as sexualidades por meio de filmes, sejam eles quais forem, desde que abordem o assunto, não é algo simplório, dada a dimensão da temática e grande falta de informação que afeta a muitas pessoas. É importante, e preciso, o entendimento do tema em toda a sua amplitude, e também de que os assuntos abordados dentro da sexualidade estão ficando cada vez mais diversificados.

Pensando nisso, o cinema entra como uma alternativa simples, todavia sem deixar de ser sério e crítico, de abordar aspectos pontuais relacionados às diversas manifestações da sexualidade (CHASKO E PREVIATO, 2013)

No caso do uso do cinema para a formação e informação acerca das questões da sexualidade, diversidade sexual e de gênero, os participantes "são 
capazes de se identificar com o drama, sofrer com o personagem (...), pois o sofrimento e as alegrias no filme representados dizem respeito à condição humana." (ARAUJO; VOSS, 2009).

Os dados evidenciam que boa parcela dos professores (40\%) acredita que é da responsabilidade do professor de Ciências e/ou Biologia abordar sobre sexualidade em suas aulas (Tabela 1).

Tabela 1 - Qual (ou quais) disciplinas devem abordar a temática da sexualidade?

\begin{tabular}{cc}
\hline Somente Ciências/Biologia & 4 \\
Psicologia e Biologia & 1 \\
Não responderam & 1 \\
Todas & 4 \\
\hline Total & 10 \\
\hline
\end{tabular}

Fonte: Elaborado pelos autores

Muitos professores acreditam que a sexualidade está ausente na infância, e só desperta na puberdade, o que justifica a não abordagem do tema na educação infantil.

Quanto a opinião dos professores em relação à disciplina de ciências/biologia e os assuntos sobre sexualidade, mesmo quando são assuntos relacionados aos aspectos culturais e históricos, é necessário que outros atores da comunidade escolar se envolvam nos trabalhos, pois a responsabilidade não deve ser delegada apenas aos professores de ciências/biologia.

Os dados evidenciam também que os professores consideram importante abordar questões relativas à sexualidade com os alunos, principalmente porque consideram que os alunos têm muito interesse, além de ser um assunto que eles gostam. Entretanto, fica evidente que há dificuldade em falar sobre o tema. 


\section{CONSIDERAÇÕES FINAIS}

A sexualidade está presente em todos os espaços, em casa, na escola, na rua e é motivo de piadinhas, risos, cochichos, porque ainda é algo que causa certo mistério, tanto para quem a está desvendando, como é o caso dos alunos adolescentes, quanto para quem recebe a incumbência de ensinar e orientar acerca da sexualidade de outrem, como é o caso dos professores, educadores e pais dentre outros.

A temática sexualidade dentro da escola, muitas vezes é delegada ao professor de Ciências e/ou de Biologia, que cumpre o papel de orientador sexual, trabalho que deveria ser de toda a comunidade escolar, conforme preveem os temas transversais dos PCNs (BRASIL, 1997).

Como os conteúdos a serem trabalhados são muitos, e as escolas, em sua maioria, não têm um projeto multidisciplinar para trabalhar essa temática, a sexualidade acaba sendo abordada nas aulas de Biologia e/ou de Ciências, que trabalham apenas os aspectos biológicos, tais como aparelho reprodutor masculino e feminino, os órgãos sexuais, as DST's e os métodos contraceptivos, sem trabalhar os aspectos psicológicos e socioculturais (RODRIGUES E SCHEID, 2008).

De fato nos parece que o que deve ocorrer é a prática da interdisciplinaridade no que toca à sexualidade, e que todos os profissionais da educação estejam preparados para falar, partindo, ou não, do conteúdo de suas disciplinas.

Neste sentido, é reforçada a importância da formação continuada acerca do tema para que mudanças se efetivem na escola e promovam a construção de uma sociedade sexualmente sadia.

Acreditamos, assim como Haguette (1995), que a educação para uma saúde sexual é um dos recursos que poderão responder à necessidade de transformação social, dado seu papel na transmissão dos conhecimentos, na formação do pensar e na responsabilidade pela mudança de comportamentos. 


\section{REFERÊNCIAS BIBLIOGRÁFICAS}

ALVES, J. C. S.; CHAVES, A. C. L. As necessidades e dificuldades da orientação sexual na visão dos professores de ciências de Porteirinha - MG. In: VI ENPEC- Encontro Nacional de Pesquisa em Educação em Ciências, 2007, Florianópolis. Anais... Florianópolis, 2007. p. 1-12.

ARAUJO, A. R.; VOSS, R. C. R. Cinema em sala de aula: identificação e projeção no ensino/aprendizagem da Língua Inglesa. Conexão Comunicação e Cultura, Caxias do Sul, v. 8, n. 15, jan./jun. 2009.

BISCOLI, C.; FAVARÃO, N.R.L.; FEITEN, R.H.; SOUZA, A.C.P.; PERPÉTUO, C.L. Sexualidade em sala de aula: um estudo da produção de sentidos. Arq. Ciênc. Saúde Unipar, Umuarama, 9(1), jan./abr. p.47-55, 2005.

BRASIL. Secretaria de Educação Fundamental. Parâmetros curriculares nacionais: introdução aos parâmetros curriculares nacionais / Secretaria de Educação Fundamental. - Brasília: MEC/SEF, 126p. 1997.

BRÍCIO, V.N.; LEMOS, F.C.S.; MAUÊS, J. Pensando sobre os objetos relações de gênero e sexualidade: inquietações foucaultianas. In: SOUZA, L.L.; GALINDO, D.; BERTOLINE, V. (Orgs). Gênero, Corpo e @tivismos. CuiabáMT: UFMT, 2012.

CHASKO, J.; PREVIATO, R. Mostra de Cinema da Diversidade Sexual em Cascavel: Cinema em ambiente escolar. In: XI Encontro Nacional Universitário sobre Diversidade Sexual. 2013, Matinhos - PR - UFPR. Anais... Matinhos, 2013.

FIGUEIRÓ, M. N. D. Formação de Educadores sexuais: adiar não é mais possível. Campinas, SP: Mercado de Letras, Londrina, PR: Eduel, 2006.

FOUCAULT, M. História da sexualidade II: o uso dos prazeres. Rio de Janeiro: Graal, 2007.

GIL, A.C. Métodos e técnicas de pesquisa social. 5. ed. São Paulo: Atlas, 1999.

HAGUETTE, T.M.F. Metodologias qualitativas na sociologia, 4. Ed. Petrópolis: Vozes. 1995.

HARDOIM, E. L.; MIYAZAKI, R.S. Saúde e Sexualidade. Cuiabá: UAB/UFMT, 2012.

LÜDKE, M.; ANDRÉ, M. E. Pesquisa em educação: abordagens qualitativas. 5a edição. São Paulo: Editora Pedagógica e Universitária, 1986. 123p. 
MAIA, A. C.; ARANHA, M. S. Relatos de professores sobre manifestações sexuais de alunos com deficiência no contexto escolar. Interação em Psicologia, São Paulo, v. 9, n. 1, p. 103-116, 2005.

NOGUEIRA, D.M. Gênero e Sexualidade na educação. In: I Simpósio sobre Estudos de Gênero e Políticas Públicas. 2010, Londrina, Universidade Estadual de Londrina. Anais....Londrina, 2010.

NUNES, C. A. Desvendando a sexualidade. $7^{7}$. ed. Campinas: Papirus, 2005.

OLIVEIRA, R. R. S.; BEZERRA, V. L. M. S. O papel do professor nas discussões sobre sexualidade: uma reflexão sobre a educação sexual na escola. In: III Seminário Nacional Gênero e Práticas Culturais, 2011. João Pessoa/PB. Anais... João Pessoa, 2011.

RODRIGUES, C. P.; WECHSLER, A. M. A sexualidade no ambiente escolar: a visão dos professores de educação infantil. Cadernos de Educação: Ensino e Sociedade, Bebedouro-SP, 1 (1): 89-104, 2014.

RODRIGUES, L. R.; SCHEID, N. M. J; Os conhecimentos básicos que os adolescentes possuem sobre sexualidade e o papel do professor de Biologia neste contexto. Educação, v. 33, n. 3, set/dez. 2008.

SEDUC - MT. Secretaria de Estado de Educação do Estado de Mato Grosso <http://www.seduc.mt.gov.br/Paginas/default.aspx> acessado em 26 de Novembro de 2015.

SCHLIEMANN, A. P. Sexualidade - adolescência - deficiência mental: um desafio a pensar. In: Simpósio Internacional do Adolescente, 2., 2005. São Paulo. Anais... São Paulo, 2005.

SOUSA, E.; SANTOS, C. Educação Sexual na Escola: Descontruindo mitos e preconceitos acerca da sexualidade, gênero e diversidade sexual. In: VI Colóquio Internacional "Educação e Contemporaneidade", 2012. SE/Brasil. Anais...SE/Brasil, 2012.

TIBA, I. Adolescência: o despertador do sexo. São Paulo: Ed. Cortez, 1994.

YARED, Y.B.; LOCKS, G.A. Educação e Sexualidade: a compreensão de professores de ciências biológicas sobre a diversidade sexual. Revista PerCursos, Florianópolis, v.13, n.02, pp.155-168, jul./dez. 2012. 